\title{
PSICANÁLISE E UMA ONTOLOGIA POLÍTICA IDENTITÁRIA: LEITURA SOBRE A EXPRESSÃO "CULTURA NEGRA"
}

Psychoanalysis and an Identity Political Ontology: Reading about the Expression "Black Culture"

Psicoanálisis y una Ontología Política de Identidad: Lectura sobre la Expresión "Cultura Negra”

Psychanalyse et Ontologie Politique identitaire : Lecture de l'Expression "Culture noire "

doi $10.5020 / 23590777 . r s . v 20 i E s p 2 . e 8916$

\section{Jacqueline de Oliveira Moreira 9}

Professora do Programa de Pós-Graduação em Psicologia da PUC Minas. Doutora em Psicologia Clínica pela PUC-SP. Mestre em Filosofia pela UFMG. Psicanalista. Bolsista Produtividade CNPq PQ2. Membro do GT da ANPEPP "Psicanálise, Clínica e Política”.

\section{Alessandro Pereira dos Santos 9}

Doutorando do Programa de Pós-graduação em Psicologia da PUC Minas, bolsista CAPES. Mestre em Psicologia pela PUC Minas, Especialista em Segurança Pública e Sistema de Justiça Crimanal pela Fundação João Pinheiro, Graduado em Psicologia pela PUC Minas.

\section{Fídias Gomes Siqueira 9}

Psicanalista. Doutorando em Psicologia (Teoria Psicanalítica), Mestre em Psicologia (Teoria Psicanalítica) pela FAFICH/UFMG, Graduação em Psicologia pela PUC Minas. Pesquisador colaborador e Co-coordenador do Programa de Extensão Já É do Núcleo PSILACS - Psicanálise e Laço Social no Contemporâneo da UFMG.

\section{Ana Carolina Dias Silva 9 iD}

Mestranda do Programa de Pós-graduação em Psicologia da PUC Minas, bolsista CAPES. Graduada em Psicologia pela UFMG, com ênfase em Processos Clínicos e Formação Complementar Aberta em Subjetividades Políticas e Territórios.

\section{Resumo}

O presente artigo pretende apresentar algumas contribuições da psicanálise para pensar o contexto das minorias, especificamente o tema da cultura negra. O fio da política é apresentado a partir da discussão a respeito da exclusão no espaço social e a consequente segregação. Considerando as ambiguidades caracterizadas pelas relações de igualdade e diferença apresentadas em Hannah Arendt, discutimos como, nessa construção do reconhecimento da diferença em um campo igualitário, encontram-se também mecanismos de domínio, entre eles, o racismo. Em seguida, por meio da leitura foucaultiana, buscamos identificar os dispositivos de poder no tecido social no que se refere à luta das raças, sendo a ideia do corpo atravessado pelo contexto sócio-histórico e cultural um elemento que apresenta o racismo como mecanismo de segregação. Seguindo os passos da discussão sobre diferença e segregação, introduzimos o pensamento de Giorgio Agamben e a dimensão da vida nua enquanto elemento central na política moderna ocidental. Após essa articulação, que buscou abordar o racismo correlato à segregação, passamos à apresentação da construção da cultura negra no contexto brasileiro. Tomamos essas elaborações tanto em sua vertente que tenta recuperar as raízes da matriz africana, passando por aquelas estigmatizantes em relação a um referenciamento ao branco, quanto aquelas denegatórias, que buscam neutralizar as especificidades de tal movimento. Concluímos essas reflexões sugerindo que a questão da identidade negra brasileira deve ser orientada pelo movimento constante de significação e ressignificação. Nessa construção, as questões sobre a relação entre oprimidos e opressores entra em voga, o que nos levou a articular o pensamento de Ernesto Laclau. Por fim, retomamos em Freud e Lacan as construções a respeito da diferença e o mal-estar que produz o encontro do sujeito com a civilização.

Palavras-chave: psicanálise; política; cultura negra. 


\section{Abstract}

This article intends to present some contributions from psychoanalysis to think about the context of minorities, specifically the theme of black culture. The policy thread is presented from the discussion about exclusion in the social space and the consequent segregation. Considering the ambiguities characterized by the relations of equality and difference presented in Hannah Arendt, we discuss how, in this construction of the recognition of the difference in an egalitarian field, there are also mechanisms of domination, among them, racism. Then, through Foucault's reading, we seek to identify the devices of power in the social fabric concerning the struggle of races, with the idea of the body crossed by the socio-historical and cultural context an element that presents racism as a mechanism of segregation. Following the steps of the discussion on difference and segregation, we introduce Giorgio Agamben's thought and the dimension of naked life as a central element in modern Western politics. After this articulation, which sought to address racism related to segregation, we proceed to the presentation of the construction of black culture in the Brazilian context. We take these elaborations both in their strand that tries to recover the roots of the African matrix, passing through those stigmatizing about referencing the white, and those denegatory ones, which seek to neutralize the specificities of such movement. We conclude these reflections by suggesting that the issue of Brazilian black identity must be guided by the constant movement of meaning and reframing. In this construction, questions about the relationship between the oppressed and the oppressors come into vogue, which led us to articulate Ernesto Laclau's thinking. Finally, we return to Freud and Lacan's constructions regarding the difference and the malaise that produces the encounter of the subject with civilization.

Keywords: psychoanalysis; politics; black culture.

\section{Resumen}

El presente trabajo pretende presentar algunas contribuciones del psicoanálisis para pensar el contexto de las minorías, especificamente el tema de la cultura negra. El hilo de la política se presenta a partir de la discusión a respecto de la exclusión en el espacio social y la consecuente segregación. Considerando las ambigüedades caracterizadas por las relaciones de igualdad y diferencia presentadas en Hannah Arendt, discutimos como, en esta construcción del reconocimiento de la diferencia en un campo igualitario, se encuentran también mecanismos de dominios, entre ellos, el racismo. En seguida, por medio de la lectura foucaultiana, buscamos identificar los dispositivos de poder del tejido social en lo que se refiere a la lucha de las razas, siendo la idea del cuerpo traspasado por el contexto socio-histórico y cultural un elemento que presenta el racismo como mecanismo de segregación. Siguiendo los pasos de la discusión sobre diferencia y segregación, introducimos el pensamiento de Giorgio Agamben y la dimensión de la vida desnuda mientras elemento central en la política moderna occidental. Después de esta articulación, que buscó enfocar el racismo relacionado a la segregación, pasamos a la presentación de la construcción de la cultura negra en el contexto brasileño. Tomamos estas elaboraciones tanto en su vertiente que intenta recuperar las raices de la matriz africana, pasando por aquellos estigmas en relación a una referenciación al blanco, cuanto a aquellas de rechazo, que buscan neutralizar las especificidades de tal movimiento. Concluimos estas reflexiones sugiriendo que la cuestión de la identidad negra brasileña debe ser orientada por el movimiento constante de significación y resignificación. En esta construcción, las cuestiones sobre la relación entre oprimidos y opresores entran en acción, lo que nos llevó a articular el pensamiento de Ernesto Laclau. Por fin, retomamos en Freud y Lacan las construcciones a respecto de la diferencia y el malestar producido por el encuentro del sujeto con la civilización.

Palabras clave: psicoanálisis; política; cultura negra.

\section{Résumé}

Cet article se propose de présenter quelques contributions de la psychanalyse pour réfléchir au contexte des minorités, en particulier le thème de la culture noire. Le fil politique est présenté à partir de la discussion sur l'exclusion dans l'espace social et de la ségrégation qui en résulte. Considérant les ambiguïtés caractérisées par les relations d'égalité et de différence présentées dans Hannah Arendt, nous discutons comment, dans cette construction de la reconnaissance de la différence dans un champ égalitaire, il y a aussi des mécanismes de domination, parmi lesquels, le racisme. Ensuite, à travers la lecture de Foucault, nous cherchons à identifier les dispositifs de pouvoir dans le tissu social à l'égard de la lutte des races, avec l'idée du corps, traversé par le contexte socio-historique et culturel, un élément qui présente le racisme comme un mécanisme de ségrégation. En suivant les étapes de la discussion sur différence et ségrégation, nous introduisons la pensée de Giorgio Agamben et la dimension de la vie nue comme un élément central de la politique occidentale moderne. Après cette articulation, qui visait à aborder le racisme lié à la ségrégation, nous procédons à la présentation de la construction de la culture noire dans le contexte brésilien. Nous prenons ces élaborations à la fois dans leur aspect qui tente de récupérer les racines de la matrice africaine, en passant par celles stigmatisantes par rapport à une référence au blanc, et aussi par celles de négation, qui cherchent à neutraliser les spécificités de tel mouvement. Nous concluons ces réflexions avec la suggestion que la question de l'identité noire brésilienne doit être guidée par le mouvement constant de signification et de recadrage. Dans cette construction, les questions sur la 
relation entre opprimés et oppresseurs entrent en vogue, ce qui nous a conduit à articuler la pensée d'Ernesto Laclau. Enfin, nous revenons aux constructions de Freud et de Lacan sur la différence et le malaise qui la rencontre du sujet avec la civilisation produit.

Mots-clés : psychanalyse ; politique ; culture noire.

A primeira força que nos move nesta reflexão é o desejo de efetivar o convite de Laurent (1999) para a construção de uma posição cidadã da psicanálise. Nas palavras do autor, "há que se passar do analista fechado em sua reserva, crítico, a um analista que participa; um analista sensível às formas de segregação; um analista capaz de entender qual foi sua função e qual lhe corresponde agora" (Laurent, 1999, p. 8). Nesse sentido, interrogamo-nos sobre as possíveis contribuições da psicanálise para se pensar a política das militâncias, especificamente as que se articulam com o tema da negritude. Inicialmente, trabalharemos a noção de política a partir do pensamento de Hannah Arendt, Michel Foucault e Giorgio Agamben, passando para uma análise da construção da expressão "cultura negra". Em seguida, utilizamos as construções de Ernesto Laclau para discutir as relações entre universal e particular na constituição de identidades coletivas como chave de leitura para a articulação do movimento negro, localizando seus pontos positivos e suas limitações. Por fim, ocupamo-nos da psicanálise para discutir como a dimensão subjetiva do sofrimento psíquico é indissociável da dimensão social.

Sabemos que a ontologia se dedica ao estudo das propriedades gerais do ser e dos seres. Assim, pensamos uma ontologia política identitária como a criação de um ser que se constitui a partir de um conjunto de seres, mas que, por estar contido no mesmo conjunto, pode ser considerado como um ser, uma pluralidade em uma unidade. Em relação à questão da ontologia, não podemos nos esquecer da advertência de Frantz Fanon (1952/2008, p. 104) no ponto específico da negritude: "A ontologia, quando se admitir de uma vez por todas que ela deixa de lado a existência, não nos permite compreender o ser negro. Pois o negro não tem mais de ser negro, mas sê-lo diante do branco". Nesse sentido, anuncia-se, com Fanon, um desafio para as políticas identitárias que pensam o conjunto dos negros como um, pois essa ação pode deixar de lado a existência, a experiência singular de diferentes grupos e sujeitos. A advertência não se constitui como uma crítica que pretende a deslegitimação de uma importante ação de reconhecimento e transmissão de valores de vida, mas se localiza no campo do desejo de ampliar a potência dessas ações. Para tal argumentação, esse trabalho se vale de uma articulação entre psicanálise e política no contexto da construção identitária da cultura negra brasileira.

Acreditamos que os movimentos de valorização da cultura negra podem se enriquecer com as reflexões do psiquiatra, filósofo e marxista negro da Martinica, Frantz Fanon, que nos oferece uma importante reflexão sobre o uso colonizador da psicopatologia e também influencia pensamentos decoloniais e anticoloniais. Para ele, a inferiorização "é o correlato nativo da superiorização europeia. Precisamos ter a coragem de dizer: é o racista que cria a inferioridade" (Fanon, 1952/2008, p. 90). O autor considera que a construção da imagem do negro como um elemento exótico ocorre a partir do olhar do branco:

É evidente que o malgaxe pode perfeitamente suportar não ser branco. Um malgaxe é um malgaxe; ou melhor, um malgaxe não é um malgaxe: existe absolutamente uma "malgaxice". Se ele é malgaxe, é porque o branco chegou, e se, em um dado momento da sua história, ele foi levado a se questionar se era ou não um homem, é que lhe contestavam sua humanidade. Em outras palavras, começo a sofrer por não ser branco, na medida em que o homem branco me impõe uma discriminação. (Fanon, 1952/2008, p. 94)

Assim, na concepção proposta por Fanon, no momento em que a cultura branca se encontra com a cultura negra, a primeira produz uma ação de opressão, inferiorização e até de aniquilamento da segunda. Efeito que perdura ao longo da história e que é sentido na pele:

O judeu só não é amado a partir do momento em que é detectado. Mas comigo tudo toma um aspecto novo. Nenhuma chance me é oferecida. Sou sobredeterminado pelo exterior. Não sou escravo da "ideia" que os outros fazem de mim, mas da minha aparição. Sinto, vejo nesses olhares brancos que não é um homem novo que está entrando, mas um novo tipo de homem, um novo gênero. Um preto! (Fanon, 1952/2008, p. 108)

A marca que salta ao olhar através da cor da pele impacta a construção da imagem corporal do sujeito negro, como revela o autor: "O homem de cor encontra dificuldades na elaboração de seu esquema corporal. O conhecimento do corpo é unicamente uma atividade de negação. (...) Então o esquema corporal, atacado em vários pontos, desmoronou, cedendo lugar a um esquema epidérmico racial" (Fanon, 1952/2008, pp. 104-105).

Nesse contexto, como construir uma imagem narcísica a partir de um corpo marcado na pele? Fanon divide com o leitor sua dor: 
Fiz um balanço completo de minha doença. Queria ser tipicamente negro - mas isso não era mais possível. Queria ser branco - era melhor rir. E, quando tentava, no plano das ideias e da atividade intelectual, reivindicar minha negritude, arrancavam-na de mim. Demonstravam-me que minha iniciativa era apenas um polo na dialética. (Fanon, 1952/2008, p. 120)

Como realizar o giro dialético do reconhecimento de si e ser uma consciência de-si, para-si e para-uma-outra? Para Fanon (1952/2008, p. 103), “bem que existe o momento de 'ser-para-outro', de que fala Hegel, mas qualquer ontologia se torna irrealizável em uma sociedade colonizada". Uma sociedade que localiza o negro a partir de uma oposição com o branco e como um sujeito de menor densidade humana não cria possibilidades de um reconhecimento, ou seja, um dos polos da dialética fica em uma posição de submissão. Assim, Fanon (1952/2008, p. 95) anuncia que "o negro não deve mais ser colocado diante deste dilema: branquear ou desaparecer, ele deve poder tomar consciência de uma nova possibilidade de existir". Aqui, a questão da constituição identitária entra em cena.

As questões apresentadas por Fanon precisam ser consideradas pelos psicanalistas no seu cotidiano de trabalho. Entretanto Reis (2005, p. 151) sugere que isto ainda não vem recebendo a devida atenção dos profissionais da psicanálise: "Mas, e os analistas? Sempre que pergunto a eles se atendem negros, geralmente dizem que têm ou já tiveram algum analisante, mas que nunca se perguntaram pela questão racial. NUNCA! Como podemos ler este fenômeno?’. O psicanalista negro argumenta que "o cotidiano da clínica com pacientes negros é formado pelo comum da neurose, da depressão, das perdas e da dificuldade em lidar com elas". Alerta, contudo, para a necessidade de a questão dos negros ser discutida "como sintoma social e individual que traz, para o sujeito que porta o atributo cor negra, um sofrimento psíquico” (Reis, 2005, p. 150).

Com base nesse contexto, este artigo busca articular política e psicanálise a partir de uma leitura possível sobre a expressão "cultura negra".

\section{Política e Políticas: Acolhida da Identidade e da Diferença}

Não buscaremos, neste artigo, definir o conceito de política, mas propomos uma breve reflexão sobre o tema partindo das contribuições de alguns autores, especialmente Arendt, Foucault e Agamben, e, posteriormente, trabalharemos as articulações entre política e psicanálise.

Procuramos uma reflexão sobre o conceito de política que oriente nossa argumentação a partir da perspectiva racial e de sua dimensão identitária. Entretanto é importante lembrar que, ao tratarmos desse tema, não podemos desconsiderar o papel das barreiras sociais no favorecimento da exclusão. Assim, as trilhas que pretendemos seguir levam em consideração a dimensão da invisibilidade e da indiferença que, segundo Soares (2004), se articulam em nossa sociedade com o problema da violência engendrada nas questões raciais. Para o autor, o estigma e o preconceito são formas de tornar alguém invisível e, se a exclusão porta a marca da invisibilidade, produz, também, indiferença, capaz de anular a pessoa e levar ao desaparecimento da singularidade.

Assim, a diferença e a singularidade são questões inerentes à perspectiva de uma política identitária. Esses temas podem ser pensados na relação com a segregação. A política, portanto, se torna nosso elemento de análise diante de problemas como a minimização das ações públicas por um Estado que ainda não assumiu sua responsabilidade pela garantia da cidadania e dos direitos humanos. Identifica-se, portanto, um hiato no campo das políticas identitárias, uma falha não suprida pelo Estado, que se agrava em decorrência dos processos políticos de conformação das sociedades contemporâneas com o estreitamento dos espaços de inclusão e com o aumento da dificuldade de suportar a diferença mais radical.

Ao tratar do tema da política, Aristóteles (1999) afirmava que o Estado é uma comunidade definida com alguma finalidade. A formação de uma comunidade política se tornava a forma mais elevada de comunidade e, nesse sentido, introduz a hierarquia como um problema ao estabelecer um sistema de relações e de diferenças. O pensador também define o homem como um animal político por ter o dom da palavra, porém nem todos os seres humanos seriam vistos dessa maneira, apenas aqueles considerados como cidadãos.

À definição de "homem”, Aristóteles (1999) acrescenta, portanto, a definição de "cidadão". Tal conceito vem juntamente com a composição do Estado, que se dá pela soma dos cidadãos, que, por sua vez, seriam definidos em função do significado que teriam para cada Estado. A definição de "cidadão" melhor se aplica a uma democracia e é aquilo que nos torna capazes de participar da autoridade do Estado em que vivemos. Assim, o cidadão deve ter a oportunidade de participar de um governo, sendo a cidadania definida pela possibilidade de participar dos privilégios da lei.

A partir dessa definição de política, cidadão e cidadania, que envolve hierarquia e espaço de fala, avançamos para o campo em que a política se caracteriza pela marca da violência, pois, como vimos, nem todos são cidadãos. Arendt (1994) afirma que a violência decorre da desagregação do poder, constituindo a perda da capacidade de agir em conjunto. Assim, para a autora, a história da diferença, da ideologia e das relações entre os povos é marcada por perseguições. Ao mesmo tempo, Arendt situa a questão da igualdade de condições na base da justiça e destaca a dificuldade de se explicar a 
diferença entre as pessoas, principalmente diante da tendência de se formarem grupos mais fechados em relação a outros indivíduos que se julgam iguais.

A igualdade como fato social encontra dificuldade de se tornar um princípio regulador da organização política, ressalta Arendt (1994), que ainda aponta a questão da diferença entre os indivíduos como desafio da modernidade e, ao mesmo tempo, um perigo quando o confronto entre um homem e seu semelhante perde a proteção das condições diferenciadoras. Por um lado, é preciso a igualdade para garantir acesso à política; por outro, não conseguimos enfrentar a questão do respeito e do reconhecimento pela diferença e, por vezes, o confronto entre os homens anula o reconhecimento dessa diferença, mas não produz a igualdade como princípio de justiça. Queremos afirmar que igualdade e diferença não são antônimas, visto que, no giro dialético, é preciso manter o reconhecimento da diferença e produzir um campo de justiça igualitária. Assim, o novo conceito de igualdade dificultou as relações raciais, uma vez que implica o reconhecimento. Quando a discriminação se torna o único meio de distinção, instaura-se uma lei universal em que certos grupos podem ser privados da igualdade cívica, política e econômica.

Para Arendt (1994), do ponto de vista político, a raça implica o fim da humanidade, o declínio dos povos e a morte antinatural do homem. Ao constatar que o racismo não era uma arma nova ou secreta, a autora também aponta sua utilização de forma meticulosa e coerente, tornando-se uma ideologia que interpreta a história como uma luta natural entre as raças. Constituinte da ideologia política do imperialismo, a questão racial irrompeu fronteiras geográficas e linguísticas, destruindo nações, e se tornou um dos mecanismos da organização política e de domínio dos povos estrangeiros.

Podemos pensar com Arendt (1989), portanto, que a raça e a burocracia são dois novos mecanismos de organização política. O racismo constitui-se num instrumento de domínio. A constituição de "homens supérfluos", advinda do imperialismo, se torna o paradigma daqueles cuja existência não é reclamada, ou seja, cujas vidas seriam descartáveis.

Tal perspectiva apontada pela autora ainda ilustra como a experiência totalitária demonstrou ser possível transformar o homem, pois, com a constituição do "inimigo objetivo", instaura-se uma nova definição da política de governo. Ao criar uma categoria que pode ser eliminada, também se demonstra que "tudo é possível”, pois, não se restringindo ao campo de extermínio, a eliminação de uma determinada categoria deixa explícita a possibilidade de degradação de qualquer ser humano. Estamos diante do homem transformado em coisa: o primeiro alvo é destruir a singularidade; na sequência, mata-se a sua individualidade. Ao tornar os homens supérfluos, a diferença se torna algo intolerável, daí a ideia de transformação do homem, e não da sociedade.

A contribuição de Foucault (2010), por sua vez, tem como ponto de partida a teoria da soberania e a relação de poder implicada. Ao analisar a sociedade a partir do enfrentamento das raças, ele demonstra a tentativa de se apagarem os vestígios do conflito de raça ao definilo como luta de classes. Ocorre, nessa perspectiva, uma recentralização do discurso da luta das raças, que se torna um discurso de poder com o predomínio de uma raça única e verdadeira no interior do corpo social, em que as instituições fazem o referido discurso funcionar como princípio de eliminação, segregação e normalização da sociedade.

Sucede a essa tentativa de apagamento uma nova estratégia, que se utiliza da ideologia racista para criar formas de controle sobre os corpos. Para Foucault (2010), a sociedade introduz um novo discurso: o racismo de Estado. Assim, o direito político do século XIX coloca o Estado em uma situação de poder, ou melhor, com acesso à tecnologia do poder que se aplica à vida dos homens. Trata-se de um poder que se volta para o corpo, não somente o corpo físico, mas o corpo enquanto ideia de população e que considera os problemas coletivos pelos efeitos econômicos e políticos que têm. As intervenções se dirigem para os fenômenos grupais.

O racismo se torna, dessa forma, o mecanismo fundamental do poder, visto que, de acordo com Foucault (2010), o funcionamento do Estado moderno passa pelo racismo. O racismo, portanto, introduz um corte entre aquele que deve viver e o que deve morrer, introduzindo censuras e fazendo funcionar uma relação do tipo guerreira, na qual o limite é estabelecido pela vida de uns e pela morte de outros. Trata-se de algo novo, compatível e indispensável ao biopoder. A função assassina do Estado só é assegurada se o seu funcionamento operar pelo racismo. Ao garantir o exercício do direito de matar, retira-se a vida sem o assassínio direto. A ênfase se coloca no assassínio indireto, expondo determinados indivíduos à morte política, à expulsão, à rejeição. Se o racismo assegura a morte, também garante o desprezo e o ódio entre as raças.

A perspectiva da politização da vida, ou seja, a maneira como a dimensão da vida é apropriada pela política e se torna um evento decisivo da modernidade, mostrando uma transformação radical das categorias político-filosóficas do pensamento clássico, é discutida por Agamben (2010). Para ele, a vida nua em sua dimensão de exclusão é o que constituirá a política ocidental e, com isto, a vida incluída a partir de uma exclusão demonstra como a exceção é consubstancial à política ocidental. Essa vida nua de que trata o autor é o paradigma do espaço político do Ocidente. Trata-se da vida matável e que também não se encontra no campo do sacrifício, o homo sacer, essa figura do direito romano arcaico na qual a vida humana se inclui no ordenamento a partir da exclusão. $\mathrm{O}$ espaço da vida nua, situado originariamente à margem do ordenamento, vem coincidir com o espaço político.

Liberada na cidade, a vida coloca em questão a vida nua do cidadão que, de acordo com Agamben (2010), é o novo corpo biopolítico da humanidade. Na democracia moderna, há uma alteração em que a vida é transformada em nova forma 
de vida, e a vida nua permanece presa à política sob a forma da exceção. Se a vida nua é o referente fundamental da política, ao entrar em primeiro plano na estrutura do Estado, torna-se o fundamento de sua legitimidade e soberania.

Se a condição da vida encontra nos mecanismos e tecnologias os recursos de seu prolongamento, devemos considerar que tais condições sustentam a eliminação da diferença, a eliminação do espaço político necessário à emergência da singularidade. $\mathrm{O}$ conflito entre as raças estabelecido pelo mecanismo do poder introduz a situação de guerra e apaga a diferença. Assim, insistir na garantia de direitos é insistir na prevalência da palavra, enquanto recurso simbólico, que nos torna animais políticos por excelência.

No contexto da sociedade brasileira, devemos ressaltar que tais mecanismos funcionam como ativadores das guerras urbanas e dos conflitos entre as classes. A perspectiva do racismo no Brasil se diferencia desta que os autores até aqui discutidos nos apresentam. O nosso contexto histórico é marcadamente inscrito e escrito pela questão racial. Sendo assim, torna-se essencial recuperarmos a constituição histórica da negritude brasileira e trabalhar a expressão "cultura negra".

\section{História e Construção da Categoria "Cultura Negra"}

Antes de discorrer sobre a "cultura negra", interessa-nos discutir brevemente o conceito de "cultura". Segundo Laraia (2001), que investiga o surgimento e a construção da cultura pelos humanos, a cultura surge na transição do substrato biológico para a vida na civilização. Nessa perspectiva, o desenvolvimento biológico não seria suficiente para a construção da civilização. Ao estabelecer marcadores teóricos para justificar o movimento da natureza da humanidade, ou melhor, da essência biológica para a vida social (compartilhada), o autor argumenta que a cultura se funda por um conjunto de regras que permitem a convivência entre os humanos e o compartilhamento de símbolos e da linguagem. Interessa-nos aqui, então, a ideia de cultura como um sistema de trocas simbólicas e regulatórias entre os humanos. É nesse sentido que pensamos a expressão "cultura negra".

Pereira (1983), em artigo intitulado Negro e cultura negra no Brasil atual, estabelece uma definição bastante genérica de cultura negra. Ele afirma:

A grosso modo, sem quaisquer preocupações com a precisão científica do conceito, as manifestações culturais mais evidentes desse contexto sincrético são vistas positiva ou depreciativamente como variantes negras da cultura nacional ou como cultura afrobrasileira. Tais são, por exemplo, certo tipo de música popular, aspectos do folclore, as religiões afros (umbanda e candomblé), os salões de bailes (gafieiras), as escolas-de-samba e grupos de folia em áreas de grande concentração de negros. (Pereira, 1983, p. 95)

Ele afirma que, em função de um espraiamento, a cultura negra pode ser considerada onipresente em todas as manifestações culturais do país, entretanto faz uma ressalva em relação à onipresença da cultura negra ao afirmar que é um fator que pode reforçar o mito da democracia racial (Pereira, 1983).

O referido autor destaca a folclorização da cultura negra como forma de reduzi-la e transformá-la em algo irrelevante. Essa folclorização incide sobre o indivíduo e o grupo racial, tornando a figura do negro algo exótico e produzindo um processo de apropriação e espoliação da cultura negra. Ao discorrer sobre a cultura no discurso e na arregimentação política do negro, o autor destaca dois polos: a massa e uma nova classe média negra, identificada pelo acesso a novos espaços de circulação na sociedade, como as universidades.

O primeiro polo seria composto pela maioria da população negra, a que chamou de massa, a qual, nos movimentos culturais, se move e passa a dar sentido à sua existência a partir da identificação grupal. Nesse sentido, a expressão da cultura negra se funde com o próprio ciclo da vida, na medida em que essa identificação cultural produz regulação, arranjos e contornos para esses modos de vida. Já o segundo polo seria uma nova classe média que surgia e que ocuparia um lugar de uma "elite negra", responsável pela conscientização política do negro. A partir do cruzamento desses polos, o autor aponta três definições de cultura negra. A primeira definição é a seguinte:

A cultura do negro é aquela que lhe é identificada historicamente. Num jogo de contradições, é uma variante cultural ao mesmo tempo estigmatizada e valorizada: estigma que alcança o grupo como expressão racial; valorização que não o beneficia aos olhos do branco. (Pereira, 1983, p. 101)

Nessa vertente, a questão cultural perpassa tanto a lógica da revalorização da cultura negra, impondo o desafio de atribuir um papel de ser social sério que não estigmatize a figura do negro, quanto a desvalorização e a estigmatização. Na segunda definição, ele afirma: 
A cultura do negro deve voltar às suas origens autênticas, africanas. Na África é que está a fonte de sua identidade cultural, deteriorada pouco a pouco na diáspora, cuja prova maior são exatamente as formas culturais negras estigmatizadas por todos e até por alguns negros. (Pereira, 1983, p. 101)

O risco dessa concepção de cultura é reforçar o exotismo em relação à imagem do negro. Ao mesmo tempo, como elemento favorável, podemos destacar a possibilidade da construção de um ponto de origem histórico e geográfico que permite que o negro reflita sobre o desenraizamento a que historicamente é submetido.

Quanto à terceira definição, ele diz: "A cultura do negro é a cultura brasileira, mesmo porque toda a cultura brasileira, graças à onipresença do elemento cultural negro, é cultura negra" (Pereira, 1983, p. 101). Essa definição é a que mais reflete uma ideologia integracionista que pode produzir o engodo e sustentar o mito da democracia racial.

Em suma, as três definições de cultura negra apontam para uma noção de cultura que incorpora as manifestações artísticas, religiosas, políticas, alimentares, entre outras, mas se diferenciam nos seguintes termos: a primeira estaria mais articulada com a imagem fenomênica do negro, estigmatizada ou valorizada pelos olhos do branco; a segunda apresenta a cultura negra como estando alicerçada em sua origem africana; e a terceira tem como princípio uma generalização da cultura brasileira como uma cultura negra.

Como herdeira dessa elite cultural referida por Pereira (1983), Gomes (2003) avança nas discussões sobre uma cultura negra ao estabelecer uma relação entre cultura negra e as lógicas simbólicas para explicar a conexão entre a África e a cultura negra no Brasil. Ela afirma:

Refletir sobre a cultura negra é considerar as lógicas simbólicas construídas ao longo da história por um grupo sociocultural específico: os descendentes de africanos escravizados no Brasil. Se partirmos do pressuposto de que o nosso país, hoje, é uma nação miscigenada, diríamos que a maioria da sociedade brasileira se encaixa nesse perfil, ou seja, uma grande parte dos brasileiros pode se considerar descendente de africanos. Porém, refiro-me aqui ao grupo étnico/racial classificado socialmente como negro. Embora alguns antropólogos tratem com desconfiança a adjetivação de uma cultura como "negra", o que importa aqui é destacar que a produção cultural oriunda dos africanos escravizados no Brasil e ainda presente nos seus descendentes tem uma efetividade na construção identitária dos sujeitos socialmente classificados como negros. (Gomes, 2003, p.4)

Em relação à questão identitária, objeto do presente artigo, ao nos reportarmos novamente ao texto de Gomes (2003) é possível localizar uma conexão entre a cultura negra e a construção de um "nós" que permite, ao mesmo tempo, reconhecimento e trocas simbólicas. Ela afirma:

A cultura negra possibilita aos negros a construção de um "nós", de uma história e de uma identidade. Diz respeito à consciência cultural, à estética, à corporeidade, à musicalidade, à religiosidade, à vivência da negritude, marcadas por um processo de africanidade e recriação cultural. Esse "nós" possibilita o posicionamento de negro diante do outro e destaca aspectos relevantes da sua história e de sua ancestralidade. (Gomes, 2003, p.5)

Segundo a autora, pensar a produção e a vivência da cultura negra é entender seu permanente movimento de significação e de ressignificação. Tal processo refere-se à criação de uma nova perspectiva identitária, sendo que, como veremos, essa identidade oferece pertencimento, mas também pode produzir exclusão. Se for possível manter o permanente processo de ressignificação, o campo do pertencimento se amplia; se, no entanto, tal movimento é impedido, gerando certa rigidez, temos um acirramento da exclusão.

Nesse sentido, como afirma Munanga (2015), é difícil a tarefa de pensar uma identidade negra, pois, a partir da diáspora, temos sujeitos negros em cidades e contextos culturais diferentes. Na tentativa de criar uma borda para pensar uma identidade negra, Munanga (2015) apresenta como componentes essenciais fatores históricos, linguísticos e psicológicos, cuja simetria representa um ideal. Com especial destaque para o fator histórico, com sua função de cimento cultural que une o conjunto dos sujeitos e dos elementos, produz-se um "sentimento de continuidade histórica vivido pelo conjunto de sua coletividade" (Munanga, 2015, p. 6). O autor prossegue destacando, de maneira similar a Gomes (2003), a importância da ancestralidade na construção da cultura negra:

Essencial para cada comunidade é reencontrar o fio condutor que a liga ao seu passado ancestral o mais longínquo possível. A consciência histórica, pelo sentimento de coesão que ela cria, constitui uma relação de segurança a mais certa e a mais sólida para o povo. É a razão pela qual [...] o afastamento e a destruição da consciência histórica eram uma das estratégias utilizadas pela escravidão e pela colonização para destruir a memória coletiva dos escravizados e colonizados. (Munanga, 2015, p. 6) 
Para o autor, essa consciência histórica é mais preservada em comunidades de base religiosa, visto que, em função de sua conexão com os orixás, mantêm viva a ancestralidade africana. Por outro lado, nas "bases populares negras sem vínculos com a comunidade religiosa de matriz africana, a consciência histórica e, consequentemente, a identidade se diluíram" (Munanga, 2015, p. 5), ficando, pois, mais difícil a construção de uma identidade cultural negra. Questiona Munanga:

De que identidade se trata? Dessa identidade mítico religiosa conservada nos terreiros religiosos? Da identidade do grupo oprimido que vacila entre a consciência de classe e de raça? Ou da identidade política de uma "raça" afastada de sua participação política na sociedade que ajudou a construir? Como se percebe, o conceito de identidade recobre uma realidade muito mais complexa do que se pensa, englobando fatores históricos, psicológicos, linguísticos, culturais, político-ideológicos, raciais. (Munanga, 2015, p. 8-9)

Retomando o objetivo de nosso artigo, portanto, podemos perguntar: como pensar sobre uma identidade negra brasileira? Devemos lembrar que Munanga indica que definir essa identidade é possível a partir da memória construída dos acontecimentos vividos, que apresenta uma dimensão tanto histórica quanto psicológica, relacionada à escravização e seu consequente desenraizamento do povo negro. Tal dimensão psicológica da escravização refere-se a uma experiência traumática que pode ser transmitida consciente e/ou inconscientemente.

Vemos que, na constituição dos movimentos sociais, as dimensões histórica e psicológica que definem a cultura negra podem ser utilizadas por uma elite negra militante para definir cultura negra como uma reação racial a uma agressão racial branca. Teremos, nesse caso, uma cultura negra baseada em sua vertente reativa. Assim, para Munanga (2015, p.10), "a questão que se coloca é saber por onde deva passar o discurso sobre essa identidade contrastiva do negro, cuja base seria a negritude; passaria pela cor da pele, pelo corpo unicamente, ou pela cultura e pela consciência do oprimido?". Tal identidade, baseada no oprimido, produziria uma alienação e uma permanente inferiorização. Para discutir tais questões, apresentaremos a construção política identitária de Ernesto Laclau e sua articulação com as relações de universalidade e particularidade.

\section{Política, Particularismo e Universalismo em Laclau}

A fim de complexificar o debate acerca das relações sociais calcadas na diferença, evocaremos o filósofo contemporâneo argentino Ernesto Laclau. Em seu livro Emancipação e Diferença, Laclau (2011, p. 49) questiona quais as relações entre particularismo e universalismo, tendo em vista o fenômeno de proliferação de identidades multiculturais "em decorrência do colapso dos lugares a partir dos quais os sujeitos universais falavam". Cabe ressaltar que, ainda que a citada proliferação passe a ser nomeada de tal forma somente após esse colapso, a vivência em decorrência dessa multiplicidade está colocada desde a origem na história da população negra.

No escopo de tal discussão, Laclau (2011) apresenta algumas correntes de pensamento que orientaram seus questionamentos: (a) a filosofia antiga clássica, que entendia haver uma clara distinção entre universal e particular, sendo aquele completamente apreensível pela razão; (b) o cristianismo, que colocava a totalidade a cargo de Deus, ou seja, fora do registro da razão, sendo necessário que os momentos universais se realizassem em realidades finitas, numa relação de encarnação em que haveria um corpo que encarna o universal enquanto "agente privilegiado da história", independente de "qualquer vínculo racional" (Laclau, 2011, p. 51); (c) a modernidade, em que uma particularidade passava a ser expressão da universalidade. Deter-nosemos nessa última corrente de pensamento para fazer avançar as discussões propostas neste trabalho.

Na modernidade, "o universal havia encontrado seu próprio corpo, mas este ainda era o corpo de uma particularidade - a cultura europeia do século XIX" (Laclau, 2011, p. 52). A indistinção do particularismo europeu se intensificou frente a quaisquer supostas funções universais. "Então, a expansão imperialista europeia tinha de ser apresentada em termos de uma função civilizatória universal, de modernização etc.".

Assim, diferentemente da lógica da encarnação, em que um poder sobrenatural atuava, na modernidade, o "privilégio ontológico" de determinados agentes sociais baseava-se na desigualdade entre as posições. Laclau (2011) argumenta que tal privilégio ontológico seria sucedido por uma superação da oposição sujeito/objeto. O problema é que seria necessário, para uma experiência completamente exitosa, que a totalidade coincidisse com a posição da maioria no processo de representação, o que nem sempre acontece. $\mathrm{O}$ oposto, as representações da classe universal através de uma "base social cada vez mais restrita", ou seja, coincidindo com o interesse de poucos, levaria, por sua vez, a uma ascensão do autoritarismo. Com essa discussão, Laclau argumenta, então, que

toda essa história aparentemente nos leva a uma conclusão inevitável: a brecha entre o universal e o particular é irreparável - o que equivale a dizer que o universal nada mais é do que um particular que, em algum momento, se tornou dominante, que não há nenhuma possibilidade de alcançar uma sociedade reconciliada. (Laclau, 2011, p. 54, grifo nosso) 
Tal afirmação pode parecer estranha a um contexto em que pretendemos analisar a construção da expressão "cultura negra", movimento coletivo de uma minoria identitária que, por vezes, tem a afirmação de sua existência como, essencialmente, um contraponto à dominação imposta pelos grupos brancos. No entanto tentaremos analisá-la na medida em que nos faz refletir sobre os avanços e as limitações na constituição identitária do movimento negro. Desde já, defendemos, com Laclau, que o caráter contingente da assunção da universalidade é um ponto central na discussão sobre ontologia política identitária, alinhado à impossibilidade de constituir uma totalidade harmoniosa do social. A tensão como efeito da contingencialidade da representação universal reflete as relações de poder que estão em jogo na constituição dos grupos e abre espaço, como veremos, para repensar a estrutura do sistema.

Cabe ressaltar que o autor aponta as dificuldades e fragilidades tanto do universalismo quanto de uma lógica particularista, chamando atenção para possíveis consequências políticas de se conceberem as relações entre universal e particular a partir da "afirmação do puro particularismo" (Laclau, 2011, p. 54), correspondente à afirmação puramente diferencial. Tal afirmação, para o autor, é a base de formas de dominação que se expressam na lógica segregatória enquanto fundamento e, assim, se tornam um mecanismo que não é exclusivo dos opressores.

Outra consequência é que "se o oprimido for definido por sua diferença do opressor, tal diferença será um componente essencial da identidade do oprimido" (Laclau, 2011, p. 58). Isso demonstra certa ambiguidade, pois sugere que, para que uma particularidade se erigisse enquanto oposição radical, seria preciso comprometer-se com a exclusão do sistema de poder, mas também a exclusão de parte de sua própria identidade, na medida em que ela se constrói em referência a tal sistema. Argumenta Laclau (2011, p.59): "sabe-se muito bem como a oposição a certas formas de poder requer uma identificação com os próprios lugares a partir dos quais a oposição se dá; como estes são, porém, internos ao sistema, há certo conservadorismo inerente a toda oposição". É por isso que, para as lutas políticas, importa que os novos contextos políticos nos quais elas se dão sejam sempre levados em conta, reconfigurando constantemente ambos os polos antagônicos.

Assim, as duas consequências apontadas por Laclau em relação à diferença demonstram como se chegaria a um confinamento identitário. No primeiro caso, a afirmação diferencial exclui a referência ao Outro. No segundo, a identidade construída puramente em referência ao opressor representa uma total negação de si ao se afirmar apenas a partir do outro.

Apesar da aparente tragicidade de sua teoria, Laclau permite que pensemos a possibilidade da inversão da ordem nos movimentos de constituição de identidades das minorias. Essa inversão não se refere ao conteúdo - o que deixaria operar as mesmas formas de opressão -, mas a uma inversão "no interior da forma do velho sistema de poder" (Laclau, 2011, p. 61). O que está em jogo é a transformação, precisamente, no que uma relação particular tem em termos universais. Laclau (2011, p. 62) reconhece, então, o protagonismo e a importância da particularidade ao afirmar que "é verdade que a afirmação de qualquer identidade específica envolve, como uma de suas dimensões, a afirmação do direito a uma existência separada". Ele ainda anuncia que essa afirmação representa a luta por uma "reforma interna do arranjo institucional" (p. 63), o que já indica que suas demandas precisam ser reconhecidas como articuladas a esse sistema para que ganhem espaço de reivindicação. É assim que a emergência da cultura negra pode passar a ser pensada a partir da elaboração das dimensões histórica e psicológica, apontadas por Munanga (2015), para muito além de se resumir a uma espécie de formação reativa.

Entendemos, assim, com Laclau, que tanto a tentativa de afirmação exclusiva das particularidades de um grupo - sendo essa a lógica puramente diferencial - quanto a tentativa de engessamento e universalização total fracassam no cenário social, excluindo qualquer possibilidade política e representando uma ameaça às identificações. Vejamos, agora, como a psicanálise apresenta a discussão sobre o tratamento da diferença.

\section{As Questões Identitárias na Perspectiva da Psicanálise e da Política}

Ao empreendermos uma reflexão sobre as perspectivas identitárias a partir de uma articulação entre a psicanálise e a política, levaremos em consideração os pressupostos teóricos e marcos conceituais que possam orientar nossa investigação e sua aplicabilidade em relação à perspectiva da identidade centrada na questão racial.

Interrogamos, pois, como a psicanálise pode pensar a perspectiva identitária em articulação com a política. Consideramos, inicialmente, que as relações de poder foram tratadas por Freud (1933/1976c) a partir de forças desiguais, que geram graus desiguais de poder. Nessa perspectiva, existe uma maioria que se encontra mais em condição de submissão do que de igualdade, havendo pouco espaço nas leis para resguardar os direitos destes que se encontram em estado de sujeição. Se, por um lado, são negados aos oprimidos direitos básicos; por outro, os supostos detentores do poder vivem acima das proibições e produzem exceções, exclusão, acirram a segregação. As condições não favorecem que os oprimidos saiam das relações de desigualdade, embora haja resistência por parte deles, e há, ainda, forte recusa dos dominantes à mudança.

Outra perspectiva tomada em Freud (1908/1976a) para pensarmos a questão identitária é o risco de aqueles que resistem - os dominados - se tornarem outlaws e, com isso, serem incluídos em uma categoria identitária cuja única perspectiva de inserção, tendo em vista sua situação irregular, se daria no campo da política disciplinar, fortalecendo a exclusão e o 
lugar de exceção. Por outro lado, ao resistir, os dominados produzem inquietação nas estruturas sociais, e essa inquietação, quando confrontada com uma tendência do mundo em produzir segregação, exclusão e isolamento, revela o papel das categorias identitárias como oposição. Se os efeitos da segregação impõem o isolamento, pela exclusão radical do outro, as modalidades de resistência, constituição e preservação da identidade visam à afirmação, e não ao apagamento, da diferença e da singularidade. No entanto, como vimos, é necessário que essa luta envolva a inversão das formas do sistema; caso contrário, tal afirmação apenas manteria os mecanismos de opressão (Laclau, 2011).

Freud (1926/1976b) destacou a perspectiva do contato e do engalfinhamento como parte do conflito. Posteriormente, salientou as modalidades de emprego de estratégias das coletividades humanas para nos manter juntos, sendo o ódio, inclusive, um dos métodos empregados (Freud, 1933/1976c). Portanto, para o autor, o conflito é inerente, mas a humanidade empregou muitas forças para manter o projeto civilizatório, inclusive certo contorno e controle do ódio, como em sua introjeção e na consequente criação do supereu.

Se a temática do ódio foi fundamental para o pensamento freudiano acerca da diferença, da intolerância e da segregação, encontramos sua atualização em Lacan (1998a), no contexto da pulsão de morte, em que a noção de agressividade aparece como mote da experiência subjetiva. A Segunda Guerra Mundial evidenciou, segundo o pensador (Lacan, 2003a), o aspecto mais sombrio da tensão entre a civilização, os homens e as minorias. Para ele, o campo de concentração foi o fato mais real e demonstrou os efeitos dos remanejamentos dos grupos sociais pela ciência. Além disso, Lacan (1998b) destaca os modos pelos quais uma sociedade pode recorrer à ciência ou ao discurso científico para localizar um grupo como representante do mal e os recursos externos utilizados para isto.

Ao tratar do lugar do criminoso em toda sociedade, Lacan (2003a) discute a posição de bode expiatório que alguns podem ocupar. Para a psicanálise, não se trata de exclusão do sujeito da sociedade, todavia o contexto das guerras possibilitou que se situasse a agressividade no ser do homem e se demonstrasse o estabelecimento de modalidades e motivações nas relações de um indivíduo com o outro e de um indivíduo ou vários indivíduos em relação a um grupo ou sociedade.

O problema da diferença é, portanto, colocado pela psicanálise a partir de várias perspectivas. Freud (1939/1976d), por um lado, tomou essa discussão considerando a situação dos judeus desde períodos mais remotos até a sua época, argumentando que a diferença é o motivo central do ódio contra os judeus e ressaltando a indiferença e a intolerância contra as pequenas diferenças como algo que se encontra na raiz do nosso narcisismo. Por outro lado, a situação dos judeus permitiu a Lacan (2003b) pensar tal contexto na perspectiva do resto, pois o campo de concentração foi, segundo o autor, a representação mais real do tratamento dado às minorias. A função desse resto evidenciou o aspecto mais sombrio da tensão entre o homem e a civilização. Parece-nos importante mencionar que estudos contemporâneos consideram a situação dos escravos nas Américas como um acontecimento mais radical de abjetificação.

Por sua vez, alguns autores pensam o lugar da psicanálise em face de temas em voga no contexto de nossas sociedades. Ayouch (2017), por exemplo, destaca a abundância de conhecimento produzido pela psicanálise em diversos temas, como a questão identitária. Segundo o autor, frente à multiplicidade de situações contemporâneas, não cabe à psicanálise impor padrões de subjetivação. Faz-se importante ressaltar essa direção, uma vez que modalidades de subjetivação são constantemente convocadas.

$\mathrm{Na}$ contemporaneidade, os sujeitos lidam com diferenças étnicas, culturais ou linguísticas e podem produzir um posicionamento alteritário vivido através da construção de grupos minoritários. Entretanto essa perspectiva da alteridade no mundo ocidental, muitas vezes, tende a inferiorizar "outro" ou a enxergá-lo como ameaçador. Esses "outros" formam grupos apenas pela exclusão.

Nesse sentido, a escuta psicanalítica, representada nesse ponto por Ayouch (2017), é definida por certa relação com a alteridade em que se busca escutar o ininteligível, sendo uma forma de compreender como o princípio de alteridade permanece vivo. Assim, como as diferenças étnicas e de gênero, as "vidas ininteligíveis" precisam ocupar um lugar central na política, nos discursos, nos debates, a fim de não incorrermos no risco da surdez frente à subjetividade de nossa época quando se trata de questões das minorias.

Para Ayouch (2017), a psicanálise enquanto prática clínica e teórica deve trabalhar para desconstruir os padrões de subjetivação, revelando a historicidade, a determinação cultural e o que, excedendo essa inscrição coletiva, faz a singularidade de um sujeito em seu sintoma. Soma-se o fato de que as singularidades do gênero, da cultura, da etnia parecem difratar - criar outro destino - a singularidade de um modelo universalizável apara explicar a variedade psíquica. Torna-se necessário pensar em especificidades e instrumentos metapsicológicos capazes de refletir a particularidade das identificações e experiências contemporâneas para que possam ir além de normatividades sociais e modelos binários.

Concordamos com Ayouch (2017) quanto ao fato de a abordagem psicanalítica não poder deixar de lado a questão identitária e das minorias. Cabe reconhecermos a existência de um grau desigual de vulnerabilidade dos sujeitos de acordo com a viabilidade de seus corpos e desejos. Cabe, ainda, considerarmos a contingência de que não se pode prescindir de um reconhecimento, pois se corre o risco de reproduzir mais vulnerabilidade sobre as minorias, mantendo-se a ausência 
de reconhecimento de sua humanidade. Essas talvez sejam as possíveis contribuições psicanalíticas para um primeiro tratamento das questões identitárias, raciais e culturais vividas pelas minorias na atualidade.

\section{Considerações Finais}

O artigo se inicia com a advertência feita por Fanon (1952/2008) a respeito de uma ontologia identitária, quando essa se resume a referenciar o negro em relação ao branco. A pergunta que orienta a constituição e reconhecimento do negro, em Fanon, apresentada na introdução, norteia a construção do artigo, que, posteriormente, articula psicanálise e política para que se possa pensar também o papel da clínica no contexto das questões raciais.

Em seguida, o fio da política é apresentado a partir da discussão a respeito da exclusão e segregação no espaço social. Para isso, a partir do pensamento de Hannah Arendt $(1989,1994)$, discutiram-se as ambiguidades que caracterizam as relações de igualdade e diferença e refletiu-se sobre como, nessa construção do reconhecimento da diferença em um campo igualitário, encontram-se também mecanismos de domínio, entre eles, o racismo. Contribuiu para a reflexão também a leitura foucaultiana (Foucault, 2010), que nos ajuda a identificar os dispositivos de poder no tecido social no que se refere à luta de raças, sendo a introdução do corpo atravessado pelo contexto sócio-histórico e cultural, um elemento que explicita o lugar do racismo como mecanismo de segregação. Seguindo os passos da discussão sobre diferença e segregação, introduzimos o pensamento de Agamben (2010) e a dimensão da vida nua enquanto elemento central na política moderna ocidental.

Após essa articulação, que buscou abordar o racismo correlato à segregação, passamos à apresentação da construção da cultura negra no contexto brasileiro. Discutiram-se elaborações a respeito da cultura negra tanto em sua vertente de busca pela recuperação das raízes da matriz africana, passando por aquelas estigmatizantes em relação a um referenciamento ao branco, quanto em suas vertentes denegatórias, que tentam neutralizar as especificidades de tal movimento.

Concluímos essas reflexões indicando que a pergunta sobre a identidade negra brasileira nos parece dever ser orientada pelo movimento constante de significação e ressignificação identitária, baseado, essencialmente, nas dimensões histórica e psicológica. Nessa construção, a relação entre oprimidos e opressores entra em voga, o que nos levou a articular o pensamento de Ernesto Laclau (2011). Vimos como esse autor oferece uma chave de leitura, que não apaga/rejeita a sustentação do conflito, mas eleva-o ao campo político por outro viés: não o conteúdo da dominação, mas a possibilidade de inversão de sua própria estrutura. O caráter contingente de uma possível totalidade sempre parcial é ressaltado para valorizar a constituição de identidades enquanto operação política por excelência, na medida em que coloca em jogo as relações insuperáveis entre particularidade e universalidade. Por fim, retomamos em Freud e Lacan as construções a respeito da diferença e o mal-estar que produz o encontro do sujeito com a civilização.

Toda essa articulação traduz uma tentativa de localizar os pontos positivos e as limitações de se buscar fazer um, fazer uma única identidade. A relação ambígua entre a constituição do laço social e o perigo de incorrer em uma cristalização das demandas nos convoca a defender a escuta da diferença sem enfraquecer as ações de reconhecimento da comunidade, considerando seu caráter contingente e a necessidade de sempre se possibilitar novas configurações. A respeito da constituição a partir da diferença, lembramos a assertiva de Stuart Hall (2006, p. 321)):

Já as estratégias culturais capazes de fazer diferença são o que me interessa - aquelas capazes de efetuar diferenças e deslocar as disposições do poder. Reconheço que os espaços conquistados para a diferença são poucos e dispersos, e cuidadosamente policiados e regulados. Acredito que sejam limitados. Sei que eles são absurdamente subfinanciados, e que existe sempre um preço de cooptação a ser pago quando o lado cortante da diferença e da transgressão perde o fio na espetacularização. Eu sei que o que substitui a invisibilidade é uma espécie de visibilidade cuidadosamente regulada e segregada.

Para além da denúncia de Hall, tratamos, neste artigo, de apresentar a construção da cultura negra em seu movimento ontológico dialético de constituição da identidade enquanto processo constante de luta.

\section{Referências}

Agamben, G. (2010). Homo sacer: O poder soberano e a vida nua I (2a ed.). Belo Horizonte: Editora UFMG.

Arendt, H. (1989). As origens do totalitarismo. São Paulo: Companhia das Letras.

Arendt, H. (1994). Sobre a violência. Rio de Janeiro: Relume-Dumará.

Aristóteles. (1999). Política. São Paulo: Abril Cultural. (Coleção Os Pensadores). 
Ayouch, T. (2017). Genre, classe, "race" et subalternité: pour une psychanalysemineure. Pourunregardneuf de lapsychanalysesurlegenre et lesparentalités. Link

Fanon, F. (1952/2008). Pele negra, máscaras brancas. Salvador: EDUFBA.

Foucault, M. (2010). Aula de 21 de janeiro de 1976. In M. Foucault, Em defesa da sociedade: Curso no Collège de France (2a ed.). São Paulo: Editora WMF Martins Fontes.

Freud, S. (1976a). Moral sexual 'civilizada' e doença nervosa moderna. In J. Strachey (Ed.), Edição standard das obras psicológicas completas de Sigmund Freud (Vol. IX, pp. 185-208). Rio de Janeiro: Imago. (Originalmente publicado em 1908)

Freud, S. (1976b). Inibições, sintomas e angústia. In J. Strachey (Ed.), Edição standard das obras psicológicas completas de Sigmund Freud (Vol. XX, pp. 95-201). Rio de Janeiro: Imago. (Originalmente publicado em 1926)

Freud, S. (1976c). Por que a guerra? (Einstein e Freud). In J. Strachey (Ed.), Edição standard das obras psicológicas completas de Sigmund Freud (Vol. XXII, pp. 237-259). Rio de Janeiro: Imago. (Originalmente publicado em 1933)

Freud, S. (1976d). Moisés e o monoteísmo. In J. Strachey (Ed.), Edição standard das obras psicológicas completas de Sigmund Freud (Vol. XXIII, pp. 13-161). Rio de Janeiro: Imago. (Originalmente publicado em 1939)

Gomes, N. L. (2003). Cultura negra e educação. Revista Brasileira de Educação, 23(2), 75-85.

Hall, S. (2006). Da diáspora: Identidades e mediações culturais. Belo Horizonte: Editora UFMG.

Lacan, J. (1998a). O estádio do espelho como formador da função do eu tal como nos é revelada na experiência analítica. In J. Lacan, Escritos (pp. 96-103). Rio de Janeiro: Jorge Zahar.

Lacan, J. (1998b). Introdução teórica às funções da psicanálise em criminologia. In J. Lacan, Escritos (pp. 127-151). Rio de Janeiro: Jorge Zahar.

Lacan, J. (2003a). Premissas a todo desenvolvimento possível da criminologia. In J. Lacan, Outros Escritos (pp. 127-131). Rio de Janeiro: Jorge.

Lacan, J. (2003b). Proposição de 09 de outubro de 1967 sobre o psicanalista da escola. In J. Lacan, Outros Escritos (pp. 248-264). Rio de Janeiro: Jorge Zahar.

Laclau, E. (2011). Emancipação e diferença. Rio de Janeiro: EdUERJ.

Laraia, R. D. B. (2001). Cultura: Um conceito antropológico (14a ed.). Rio de Janeiro: Jorge Zahar.

Laurent, E. (1999). O analista cidadão. Curinga Psicanálise e Saúde Mental, 13, 7-13.

Munanga, K. (2015). Negritude: Usos e sentidos. Belo Horizonte: Autêntica.

Pereira, J. B. B. (1983). Negro e cultura negra no Brasil atual. Revista de Antropologia, 26, 93-105.

Reis, J. T., Filho (2005). Negritude e sofrimento psíquico. Tese de Doutorado, Psicologia Clínica, Pontifícia Universidade Católica de São Paulo, São Paulo, PUC.

Soares, L. E. (2004). Juventude e violência no Brasil contemporâneo. In R. Novaes \& P. Vannuchi (Org.), Juventude e sociedade: Trabalho, educação, cultura e participação (pp. 130-159), São Paulo: Editora Fundação Perseu Abramo. 


\section{Como citar:}

Moreira, J. O., Siqueira, F. G., Santos, A. P., \& Silva, A. C. (2020). Psicanálise e uma Ontologia Política Identitária: Leitura sobre a Expressão "Cultura Negra". Revista Subjetividades, 20(Esp 2. O Contemporâneo à Luz da Psicanálise) e8916. http:// doi.org/10.5020/23590777.rs.v20iEsp2.e8916

\section{Endereço para correspondência}

Jacqueline de Oliveira Moreira

E-mail: jackdrawin@yahoo.com.br

Alessandro Pereira dos Santos

E-mail: alessandronarede@hotmail.com

Fídias Gomes Siqueira

E-mail: fidias.siqueira@gmail.com

Ana Carolina Dias Silva

E-mail: acdsilva.psi@gmail.com 